\title{
Contexto familiar e saúde bucal de pré-escolares: uma abordagem quali- quantitativa em Salvador, Bahia, Brasil
}

\author{
Family context and preschool children's oral health: a quali-quantitative \\ approach in Salvador, State of Bahia, Brazil
}

Tatiana Frederico de Almeida', Maria Isabel Pereira Vianna²

\begin{abstract}
${ }^{1}$ Mestre e Doutora em Saúde Coletiva, Cirurgiã-dentista da Secretaria Municipal de Saúde de Salvador-BA, Professora Adjunto. Escola Bahiana de Medicina e Saúde Pública - Curso de Odontologia

${ }^{2}$ Doutora em Saúde Pública. Professora Associada nível I. Departamento de Odontologia Social e Pediátrica. Faculdade de Odontologia da UFBA.
\end{abstract}

\begin{abstract}
Resumo
Introdução: Na infância a cárie dentária representa a principal patologia bucal. O cuidado familiar é necessário para a manutenção da saúde bucal da criança. Objetivo: Este estudo teve por objetivo analisar a relação entre o contexto familiar e a saúde bucal de pré-escolares, utilizando as abordagens qualitativa e quantitativa. Metodologia: $O$ estudo epidemiológico foi de corte transversal e avaliou a saúde bucal de 528 crianças de 18 a 48 meses de idade assistidas pela Estratégia Saúde da Família de Salvador-BA e entrevistou suas respectivas mães, em 2007; já o estudo qualitativo foi realizado com mães, avós e profissionais de saúde bucal, que participaram de grupos focais. Os resultados buscaram articular ambas as abordagens. Resultados: As condições de saúde bucal deste grupo foram marcadas pela prevalência e gravidade da cárie dentária. Observou-se como fatores associados à ocorrência da cárie na dentição decídua: idade da criança, renda familiar, escolaridade materna, número de moradores por cômodo, tipo de casa, relação mãe-filho e alcoolismo materno. A cárie é percebida como um problema importante. Conclusão: Ações intersetoriais e o acolhimento nos serviços são necessárias para o planejamento de estratégias de saúde bucal mais efetivas para os pré-escolares.
\end{abstract} Palavras-chave: Pré-escolar .Saúde bucal. Epidemiologia.

\begin{abstract}
Introduction: During childhood dental caries represent the primary oral disease. Family's care is necessary to maintain children's oral health. Objective: The objective of this study was to analyze the relationship between the family context and preschool children's oral health, using the quantitative and qualitative approaches. Methodology:The cross-sectional epidemiological study evaluated the oral health of 528 children with ages between 18 and 48 months, being assisted by Family Health Strategy, in Salvador, State of Bahia, and interviewed their respective mothers, in 2007; the qualitative study was carried out with mothers, grandmothers and oral health practitioners that participated in focal groups. Results: The results of this study sought to discuss both approaches. This group's oral health conditions were distinguished by the prevalence and severity of dental caries. The following factors associated to caries in deciduous teeth were observed: child's age, family income, mother's schooling, number of persons per household, type of housing, mother-son relationship and mother's alcoholism. Dental caries are perceived as a major problem. Conclusion: Intersectorial actions and the welcome offered in the service are necessary for the planning of more effective oral health strategies for preschool children. Keywords: Child, Preschool. Oral health. Epidemiology.
\end{abstract}

\section{INTRODUÇÃO}

A cárie dentária constitui-se como a doença bucal mais prevalente na infância, sendo a sua prevenção de extrema importância para a qualidade de vida da criança, por ser causa de dor, sofrimento e associar-se às condições gerais de saúde. Adicionalmente, este é um problema com possibilidades de prevenção e custos de tratamento elevados, caracterizando-se como um problema de saúde coletiva'.

Correspondência / Correspondence: Tatiana Frederico de Almeida. Escola Bahiana de Medicina e Saúde Pública, Avenida Silveira Martins, no 62, Cabula CEP. 41150-100, Salvador-BA, Brasil; tel. 99334886, e-mail: tatifrederico@yahoo.com.br
Quanto à sua etiologia, a cárie dentária é uma doença crônica, infecciosa e multifatorial². A cárie precoce na infância, termo utilizado para determinar o acometimento da lesão cariosa em criança com até 71 meses de idade ${ }^{2}$, relaciona-se a fatores biológicos, socioeconômicos e atitudes comportamentais referentes à higiene e dieta ${ }^{3,4,5}$. Todavia, as normas culturais, crenças e comportamentos, bem como as alterações psicossociais na família e fatores relacionados à oferta de serviços na infância que podem interferir na saúde bucal são temas pouco explorados na literatura ${ }^{6}$.

Nesta fase da vida os cuidados e estímulos necessários ao crescimento e desenvolvimento são fornecidos pela família7. A família representa o 
primeiro núcleo social da criança e possui um modo de vida próprio ${ }^{8}$, que pode ser compreendido à luz do modelo teórico proposto por Almeida Filho": "Modo de Vida e Saúde", o qual trata de dois domínios da vida social: o simbólico e o da cotidianidade, isto é, estilo e condições materiais de vida, respectivamente. A adequação do cuidado no contexto familiar decorre de condições estáveis de vida, tanto psicossociais quanto socioeconômicas ${ }^{10}$.

No campo da Saúde Bucal Coletiva os estudos epidemiológicos acerca da cárie precoce predominam em relação aos qualitativos ${ }^{11}$. Todavia, os últimos são fundamentais para a compreensão do processo saúde-doença bucal, afinal a forma como as pessoas percebem este processo influencia diretamente as suas práticas ${ }^{12}$. A partir do desvendamento das percepções sobre as doenças e os cuidados com a saúde bucal, o planejamento de estratégias para a promoção da saúde e prevenção de doenças deve incluir os responsáveis pelas crianças em seu contexto histórico, seu meio social e suas relações com as crianças e os espaços sociais que as abrigam.

A pesquisa em saúde utiliza as abordagens metodológicas quantitativas e qualitativas para se aproximar da realidade observada. Além de apropriado ao objeto da investigação e de oferecer elementos teóricos para a análise, o método tem que ser operacionalmente exequível. Ambas as abordagens são necessárias, porém em muitas circunstâncias são insuficientes para abarcar toda a realidade observada. Portanto, elas podem e devem ser utilizadas como complementares, sempre que o planejamento da investigação esteja em conformidade ${ }^{13}$. Assim, nesta investigação buscou-se utilizar ambas as abordagens metodológicas de maneira integrada, e seu principal objetivo foi descrever a relação entre o contexto familiar e a saúde bucal de pré-escolares.

\section{MATERIAIS E MÉTODOS}

\section{Abordagem Quantitativa}

O estudo de natureza epidemiológica faz parte de um projeto de pesquisa mais abrangente, que envolveu a realização de um estudo de coorte que avaliou a associação entre contexto familiar e saúde bucal de préescolares. Os dados deste estudo, com delineamento transversal, referem-se a avaliações realizadas no primeiro ano de acompanhamento de crianças com idade entre 18 e 48 meses, residentes em áreas de abrangência de cinco diferentes Unidades de Saúde da Família (USF) da Estratégia Saúde da Família de Salvador-BA, no período de julho a dezembro de 2007.

Foi utilizado o aplicativo Statcalc do Epiinfo versão $6.04^{14}$ para o cálculo do tamanho de amostra para um estudo de corte. Considerou-se como efeito a cárie dentária e a variável de exposição foi disfunção familiar caracterizada pela presença de alcoolismo familiar ou alteração psiquiátrica materna, de acordo com um estudo prévio realizado na capital baiana ${ }^{15}$.
Salvador está dividida em doze distritos sanitários e, em 2006, possuía 2.714 .977 habitantes. O processo de amostragem deste estudo foi realizado em duas etapas - seleção com caráter de conveniência dos distritos sanitários e sua respectiva unidade de saúde, e a amostragem aleatória simples para a seleção das crianças de 18 a 48 meses cobertas pela Estratégia Saúde da Família, contemplando os indivíduos desta faixa etária cadastrados nas USF. Considerando as diferenças socioeconômicas e do perfil epidemiológico entre os doze distritos sanitários de Salvador-BA, optouse por classificá-los em quatro grupos (condição sócioeconômica e epidemiológica muito baixa, baixa, regular e alta), utilizando-se para isso uma adaptação do indicador agregado proposto por Oliveira ${ }^{16}$.

A partir da classificação final dos distritos, conforme metodologia também utilizada por Oliveira ${ }^{16}$, foi definido um distrito representante de cada um dos grupos como unidade amostral primária. Tais distritos foram definidos de acordo com a conveniência do grupo de pesquisa envolvido neste projeto. Assim, foram definidos os seguintes distritos sanitários: Brotas, Pau da Lima, Subúrbio-Ferroviário e Barra-Rio Vermelho. Para cada um deles, foi estabelecida uma área de abrangência de uma USF para coleta de dados. Baseado na cobertura de crianças na faixa etária do estudo pelo Programa Agentes Comunitários de Saúde e Estratégia Saúde da Família em 2006, é que foi calculado o tamanho amostral de cada distrito sanitário.

Os dados deste estudo são primários, coletados em ambiente domiciliar, sob luz natural, com a criança sentada. A coleta foi realizada através de entrevista estruturada e exame bucal. Na entrevista realizada com as mães das crianças, ou cuidador principal (na ausência permanente da mãe como principal cuidadora, por exemplo, em caso de falecimento, moradia em outro bairro/local, ou cidade), utilizou-se um questionário estruturado. Os aspectos psicossociais maternos foram avaliados pela suspeita de transtornos mentais comuns identificados pelo Self Report Questionnaire SRQ-20 ${ }^{17}$, sendo que o caso foi identificado a partir de 08 ou mais respostas positivas e pelo alcoolismo de acordo com a escala $\mathrm{CAGE}^{18}$, quando o caso foi identificado a partir de duas ou mais respostas positivas. Foi utilizada uma ficha para o exame bucal, onde foram registrados dados referentes à condição de cárie dentária, conforme os critérios do ceo-d e ceo-s ${ }^{19}$.

A coleta dos dados foi realizada por equipes de estudantes de graduação da FOUFBA, devidamente treinados e calibrados, sendo observados índices satisfatórios de concordância inter e intra-examinadores. A equipe também era formada pelos Agentes Comunitários de Saúde (ACS) responsáveis pelas micro-áreas.

Realizou-se, inicialmente, a análise descritiva das variáveis de interesse. Análises bivariadas foram realizadas, considerando a presença de cárie dentária como efeito principal (variável dicotômica, ceo- $d=0$ e 
ceo-d>0) e sua associação com variáveis classificadas em condições de vida (demográficas, socioeconômicas e ambientais), estilo de vida (atitudes comportamentais, relacionais familiares e acesso a atenção odontológica) e alterações psicossociais maternas (transtornos mentais comuns e alcoolismo). Para isso foram estimadas medidas de associação (Razões de Prevalência - RP) e seus respectivos Intervalos de Confiança a 95\% (IC 95\%). Os instrumentos de coleta de dados foram revisados e os dados digitados no EPI-INFO, versão 6.0414. Para a análise dos dados foi utilizado o programa STATA $10^{20}$.

\section{Abordagem Qualitativa}

Realizou-se um estudo qualitativo em uma área de abrangência de uma USF de Salvador-BA. Os sujeitos deste estudo foram mães ou avós de crianças na faixa etária préescolar (de 18 a 48 meses de idade), moradoras da área de abrangência da USF, e profissionais de saúde bucal, especialmente cirurgiãs-dentistas (majoritariamente presentes) e ACS, que participaram de grupos focais nos meses de janeiro e fevereiro de 2009.

O grupo focal é uma estratégia grupal para realização de entrevistas em profundidade utilizada na pesquisa qualitativa. Trata-se da condução de um debate aberto e acessível: os assuntos em questão são de interesse comum, planejado para obtenção de percepções sobre um determinado tema em um ambiente permissivo e não ameaçador, é uma interação social mais autêntica do que a entrevista em profundidade individual ${ }^{21}$.

As entrevistas foram gravadas e realizadas pela pesquisadora responsável. Um roteiro semi-estruturado orientou as perguntas. Após a transcrição integral dos depoimentos, realizou-se a análise de conteúdo ${ }^{22}$, etapa onde o material transcrito e o registro das observações foram organizados segundo unidades de contexto e categorias pré-analíticas, definidas a partir da literatura e experiência da pesquisadora. As categorias foram definidas e consolidadas no transcorrer da análise, com o objetivo de avaliar a relação entre o contexto familiar e a saúde bucal infantil. Ao final, foram utilizadas as seguintes categorias analíticas: a cárie dentária em pré-escolares sob dois olhares, e cárie dentária em pré-escolares e fatores associados. Na seção de Resultados e Discussão, a entrevistadora/moderadora foi identificada como tal e as mães/avós e profissionais através de nomes fictícios. As falas apresentadas respeitaram a grafia e sintaxe utilizadas pelos participantes. O presente estudo foi aprovado pelo Comitê de Ética em Pesquisa do Instituto de Saúde Coletiva da Universidade Federal da Bahia. Os termos de consentimento foram assinados pelos participantes e responsáveis pelas crianças, após o esclarecimento dos objetivos da pesquisa.

\section{RESULTADOS E DISCUSSÃO}

A descrição dos resultados e discussão deste estudo de natureza quali-quantitativa buscou articular ambas as abordagens a partir das duas categorias de análise referidas, anteriormente, de maneira integrada e complementar.

\section{A cárie dentária em pré-escolares sob dois olhares}

No estudo qualitativo foram formados quatro grupos (dois grupos formados por oito mães ou avós de crianças na faixa etária pré-escolar, e dois grupos formados por uma cirurgiã-dentista e 12 ACS). Cada grupo participou de um grupo focal com duração de 60 a 90 minutos na sala de reunião da própria USF.

No inquérito epidemiológico de cárie dentária foram avaliadas 528 crianças, das quais 212 residiam no distrito Barra-Rio Vermelho, 28 no distrito de Brotas, 99 no distrito Pau da Lima e 189 no Subúrbio Ferroviário. A idade delas variou de 18 a 48 meses, a média foi de 33 meses de idade, e a maioria era do sexo feminino $(53,22 \%)$ (Tabela 1). Na maioria das vezes, suas mães biológicas foram entrevistadas, exceto no caso de 24 crianças $(4,55 \%)$ que eram cuidadas por avós maternas ou paternas em razão da ausência permanente de suas mães, as quais exerciam o papel da mãe e por isso também participaram da coleta dos dados.

A maior parte das crianças era negra ou parda $(85,04 \%)$, residia em domicílios com seis ou menos eletrodomésticos $(55,68 \%)$, cinco ou mais cômodos $(54,73 \%)$, com até um morador por cômodo $(57,01 \%)$, que eram construídos de tijolos $(98,11 \%)$ e o lixo era coletado regularmente (91,48\%). A renda familiar da maioria delas era de até dois salários mínimos $(67,42 \%)$. O chefe das suas famílias era o companheiro da sua mãe ou o casal (mãe e companheiro) $(64,02 \%)$, suas mães possuíam o 2 - grau incompleto ou menos anos de estudo $(60,42 \%)$ e eram casadas ou viviam com companheiros $(68,18 \%)$. A maioria das crianças não possuía irmãos na sua faixa etária $(81,44 \%)$, morava com a mãe biológica $(87,69 \%)$ e era cuidada por ela $(79,17 \%)$ (Tabela 1$)$.

No que tange aos principais hábitos de alimentação e higiene das crianças, verificou-se que $58,71 \%$ delas não eram amamentadas durante a noite, $50,19 \%$ havia sido amamentada no seio materno por menos que seis meses e a maioria consumia alimentos doces $(81,25 \%)$. A sua higiene bucal iniciava-se geralmente aos seis meses ou mais de idade $(67,99 \%)$ e em sua grande maioria, estas crianças nunca haviam recebido qualquer tipo de atenção odontológica, seja esta preventiva, educativa ou curativa $(66,29 \%)$ (Tabela 2$)$.

Quanto às alterações psicossociais identificadas nas mães das crianças, observou-se que $29,92 \%$ destas possuíam algum tipo de transtorno mental comum e $17,42 \%$ relataram alcoolismo (Tabela 2 ).

A cárie dentária apresentou uma prevalência de $16,48 \%$ entre as crianças assistidas pela Estratégia Saúde da Família de Salvador-BA (Tabela 1), sendo sua gravidade avaliada pelo ceo-d e ceo-s, que apresentaram os respectivos valores: 0,62 e 1,09. No Brasil, o pe- 
Tabela 1. Condições de vida (características demográficas, socioeconômicas e ambientais), estilo de vida (características relacionais familiares) e prevalência de cárie dentária em pré-escolares, Salvador-BA, 2007 ( $n=528$ ).

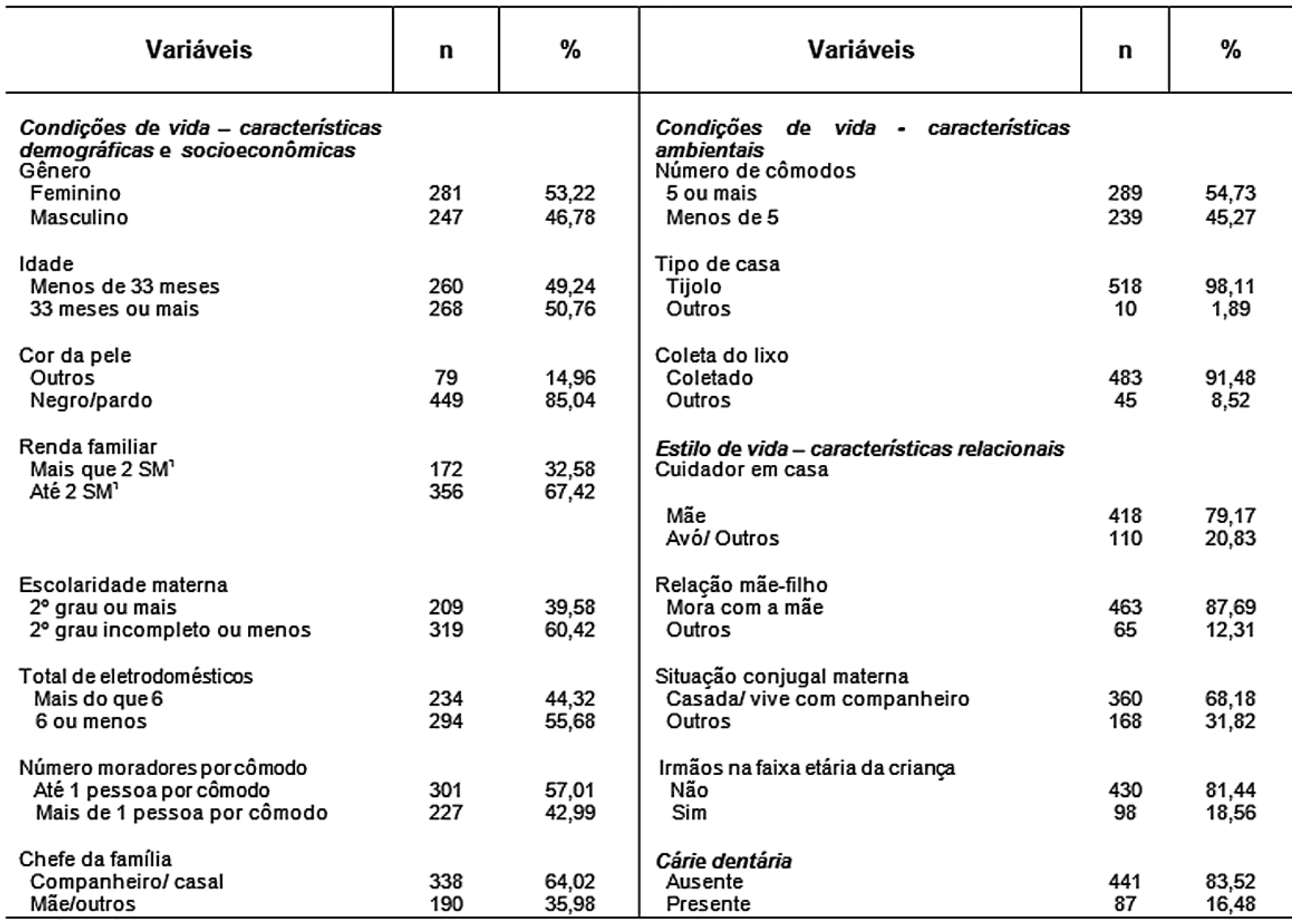

${ }^{1}$ Salário Mínimo

Tabela 2. Estilo de vida (características comportamentais e acesso a atenção odontológica) de pré-escolares e alterações psicossociais maternas, Salvador-BA, $2007(n=528)$.

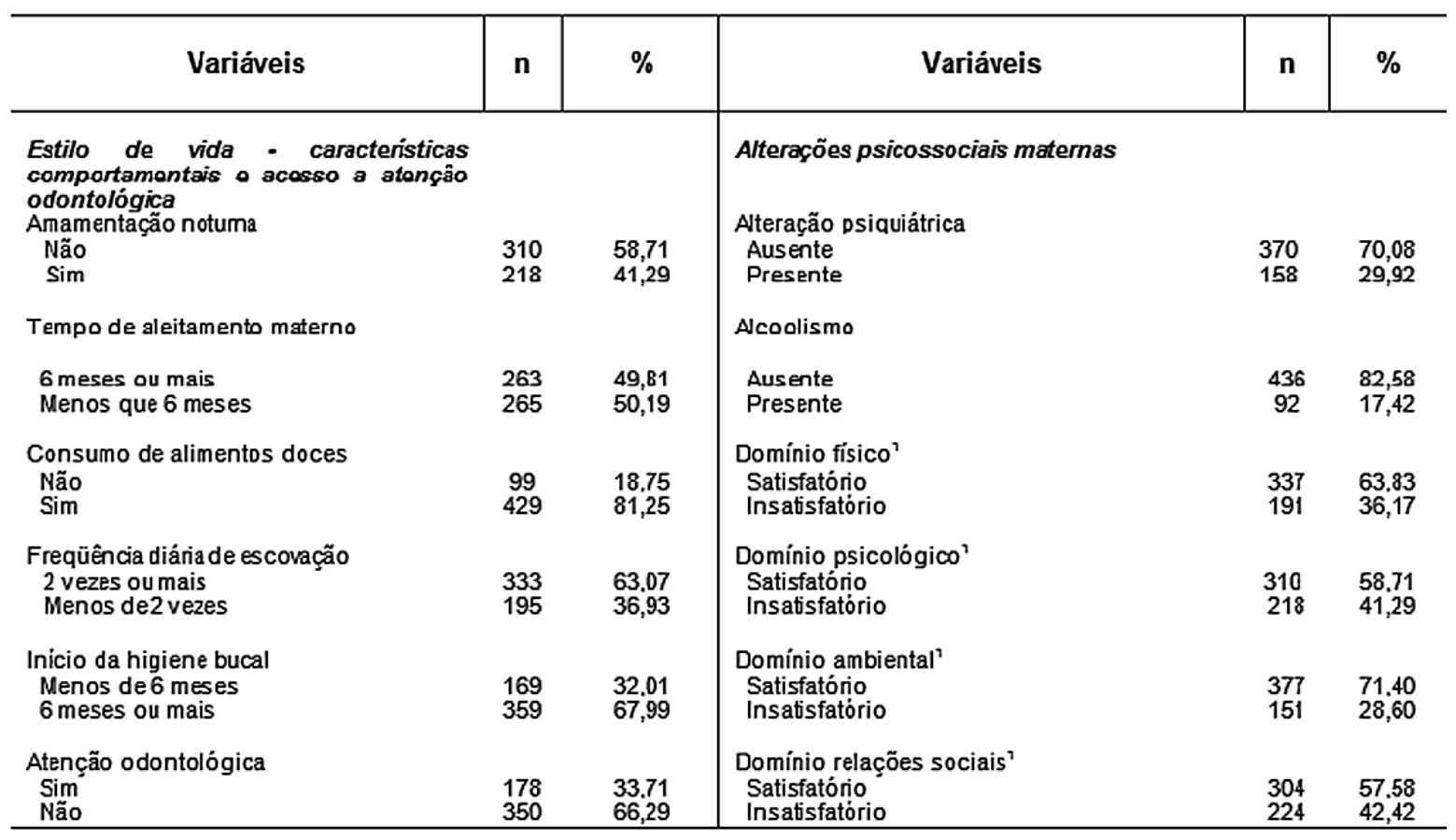

1Domínios da Qualidade de Vida Materna, segundo classificação do Who Qol-Bref 
núltimo inquérito epidemiológico nacional de saúde bu$\mathrm{cal}^{23}$ avaliou as condições bucais de crianças na faixa etária de 18 a 36 meses e revelou que cerca de $27 \%$ delas apresentaram pelo menos um dente decíduo cariado e esta prevalência subiu para cerca de $60 \%$ nas crianças com cinco anos de idade. 0 ceo-d na faixa etária de 18 a 36 meses foi de 1,07.

Em Salvador-BA o ceo-d de crianças de cinco anos, em 2005, foi igual a 1,97, sendo que a prevalência de cárie foi de $49,6 \%$. Entre os dentes atacados pela cárie dentária, $85,78 \%$ encontravam-se cavitados, ou seja, necessitando de tratamento restaurador ${ }^{24}$. Este último achado corrobora os resultados deste estudo, quando $94,17 \%$ dos dentes decíduos acometidos pela cárie em pré-escolares necessitavam de restauração, apenas 3,68\% estavam restaurados e 2,15\% já haviam sido extraídos.

A cárie dentária é percebida como a mais importante alteração bucal tanto pelas mães ou avós de crianças na faixa etária pré-escolar, quanto pelos profissionais de saúde que participaram dos grupos focais. Destaca-se que sinais e sintomas da cárie dentária são referenciados de acordo com a nomenclatura e conhecimento científicos, a exemplo de "cárie" e "cárie ativa", especialmente, entre os ACS. No entanto, os sintomas da cárie também são relatados como "esfarelamento" e "dente estragado", assemelhando-se a um processo natural, que é reforçado pela crença de que é possível a erupção do dente com cárie.

Na minha área quando eu comecei a trabalhar tinha um garotinho, ele tinha 02 anos na época, e era aquela cárie ativa, que é aquela castanhazinha (Rita, ACS).

Eu tô com uma criança que ela tá com esfarelamento do dente. Aí, a mãe disse que é por causa da sensibilidade ao açúcar, e aí o dente dela foi esfarelan-

do, esfarelando, e agora tá com uma cariezinha, tá banguela na frente (Júlia, ACS).

Eu tenho minha criança com os dentes todos estragados, já pra perder os dentes de leite e ele já não é mais dente de leite, já é o dente que nasceu que tá todo estragado (Maria da Conceição, mãe).

A percepção das mães de Fortaleza-CE sobre a cárie enquanto um problema bucal infantil também foi observado por Nations et al. ${ }^{25}$ Contudo ao se referirem a este problema elas utilizavam a linguagem popular: "dente pôdi", "estragado", "comido". A possibilidade de erupção de dentes já cariados aparece também no relato de algumas mães no estudo de Nations et al..$^{25}$, segundo uma delas o dente de seu filho "já nasceu podre". Tal concepção popular de que a cárie é um processo inevitável também foi notada em outros grupos no Brasil ${ }^{12,} 26$.
As consequências da cárie para as crianças são sentidas, principalmente aquelas relativas à dor, inflamação gengival e desenvolvimento emocional infantil.

(...) mas é um processo muito complicado [refere-se a uma criança com cárie], dolorido, a gengiva dele fica inchada (Júlia, ACS).

Aí vem esse paciente mesmo, estuda num colégio na área que a gente tava fazendo um trabalho, aí os colegas dizem: "Ah, o dente dele não tem jeito mais não, são tudo podre, num vai ficar nunca mais bom", não sei o quê. A gente conversa com eles, mas a gente vê que tem o preconceito deles, né? Tem o preconceito, né? E a criança acaba ficando retraída (Rita, ACS).

A presença precoce de cárie em crianças possui características destrutivas específicas e geralmente é acompanhada pela presença de dor e infecção, que podem gerar problemas alimentares e consequente comprometimento do desenvolvimento físico e da estética, prejudicando o convívio social infantil ${ }^{3}$.

\section{ciados}

\section{Cárie dentária em pré-escolares e fatores asso-}

Aspectos biológicos e atitudes comportamentais envolvidos no desenvolvimento da cárie, tais como, a presença de bactérias, hábitos alimentares e higiene bucal aparecem nos depoimentos como principais causas desta doença. $O$ uso de antibióticos também é apontado como agente causal.

Eu acho que tem que tá escovando porque a bactéria, ela também fica na língua. Tem que escovar até a língua, né? (Eliana, mãe).

O que tem cárie, em geral tem a dieta cariogênica. E aliada a isso, também a escovação que não é feita adequadamente (Roberta, cirurgiã-dentista).

(...) Eu não sei se é verdade, mas minha mãe sempre dizia que antibióticos estragam os dentes. Não sei se é verdade (Adriana, mãe).

A percepção da relação entre microrganismos e cárie dentária também foi verificada por outros pesquisadores ${ }^{25},{ }^{27}$. As mães entrevistadas por Nations et al. ${ }^{25}$ relacionaram a doença à presença de "lagartinha". Investigações realizadas em outros locais também concluíram que mães e profissionais tendem a interpretar a causalidade do processo saúde-doença cárie a partir de hábitos de alimentação e higiene ${ }^{26,27}$.

Historicamente, os estudos priorizaram os aspectos biológicos e atitudes comportamentais relacionadas às condições de saúde bucal, enfatizando os fatores proximais individuais de determinação das principais doenças que acometem a cavidade bucal. Dessa forma, as práticas de promoção de saúde concentraram esforços 
em estratégias que viabilizassem mudança de hábitos, basicamente, a higienização dental e o consumo reduzido e racional da sacarose. Algumas investigações, porém, têm concluído que estas estratégias são limitadas no que se refere à melhoria das condições de saúde bu$\mathrm{cal}^{28}$. Entretanto, os achados do estudo epidemiológico não revelaram associações positivas estatisticamente significantes entre aspectos comportamentais relacionados à saúde bucal, como hábitos alimentares e de higiene bucal, e cárie dentária em pré-escolares (Tabela 4), é possível que o poder do estudo tenha sido insuficiente para esta análise específica.

Ressalta-se que houve uma associação negativa, estatisticamente significante entre a não ocorrência da atenção odontológica, caracterizada neste estudo por ações educativas, preventivas e cirúrgico-restauradoras e a cárie ( $R P=0,60$, IC 95\% 0,41 0,87) (Tabela 4). Isto pode ser explicado pelo fato de que ações de saúde bucal coletiva voltadas para esta faixa etária ainda são escassas no Brasil, além disso, a visita ao dentista por crianças em tenra idade ocorre, em geral, quando já se instalou algum problema bucal. O conceito da visita preventiva ao dentista ainda não é bem estabelecido nas diferentes culturas, como ocorre com a visita ao pedia$\operatorname{tra}^{29}$.

Assim como neste estudo, algumas mães, participantes do estudo de Abreu, Pordeus e Modena ${ }^{26}$, apontaram o uso de antibióticos como causa para a cárie dentária. Segundo elas, isto ocorre devido à "fragilização" dos dentes causada pelo medicamento "forte", capaz de "matar os microrganismos e enfraquecer os dentes". Também é comum a crença de que o consumo de sulfato ferroso é responsável pela cárie precoce, como relatou uma mãe no estudo coordenado por Nations et al. ${ }^{25}$.

Os cuidados em saúde geral apresentam diferenças conforme a idade e sexo da criança.

Eu acho que eu cuido mais dela [refere-se à filha] do que dele [refere-se ao filho]. (...) Porque na idade que ele tinha, eu cuido muito mais dela do que quando ele tinha três anos (Cláudia, mãe).

Eu cuido das duas iguais. Agora, a pequenininha, por ser mais bebezinha, tem mais um carinho, mais chamego. Não que eu deixe de amar a outra, dar carinho também (Maria da Conceição, mãe).

Este comportamento relativo ao cuidado com as crianças pode ajudar a compreender a associação positiva estatisticamente significante entre idade e cárie em pré-escolares ( $\mathrm{RP}=3,05, \mathrm{IC} 95 \% 1,92$ 4,83) (Tabela 3). Possivelmente, quando estas crianças tornam-se mais velhas reduz-se o cuidado no ambiente familiar. De forma precoce, a criança torna-se responsável pelo auto-cuidado com a saúde bucal, como retrata a fala da mãe abaixo.
Até os cinco anos eu escovava. Agora ela [refere-se à filha] escova sozinha (Mirela, mãe).

Não houve associação estatisticamente significante entre sexo e cárie precoce neste estudo ( $R P=1,06$, IC 95\% 0,72 1,56) (Tabela 3), apesar das famílias referirem um maior cuidado com as meninas, como observado nas falas acima. Este comportamento também é adotado pelos informantes do estudo de Bustamante e $\operatorname{Trad}^{30}$, que consideram que as meninas precisam de mais cuidados corporais (com a roupa, higiene, penteado, arrumação e no "ficar de olho"), já os meninos precisam de mais controle e diálogo.

Posteriormente, ao longo do grupo focal, aparece no depoimento de uma dentista que o contexto familiar, marcado pela desestruturação material, psicológica e afetiva é capaz de influenciar os cuidados com a saúde bucal, sendo este um fator observado pela sua equipe nas práticas de atenção à saúde bucal. Em seguida, uma ACS comenta que a experiência de cárie da mãe é mantida nos filhos.

É o núcleo, né? Mas nem sempre esse pai, essa mãe ou está preparado, ou está fisicamente, materialmente estruturado... às vezes uma falta de preparo psicológico, emocional... Às vezes é uma desestrutura de núcleo familiar mesmo, que não conseguiu ser formado por alguma razão. A gente lida com diferentes tipos de estruturas de famílias aqui que a gente tem que tá atento no consultório, na visita domiciliar e nas capacitações que a gente faz também com os meninos [refere-se aos ACS], pra ficarem mais atentos com essas famílias mais prejudicadas, pra gente priorizar as visitas dessas famílias, porque essas são as que mais necessitam. Vamos fazer visita domiciliar, vamos olhar essas famílias mais carentes, não só financeiramente, mas a questão da higiene que pra nós em saúde bucal é importante, que acompanha uma série de fatores emocionais, ou seja, mesmo não tendo uma condição financeira, mas a família é tão desestruturada, de chegar a mal tratar, imagine cuidar da higiene (Roberta, cirurgiã-dentista).

É em relação com que ela tá falando, eu tenho uma família que a mãe tem o dente todo estragado, horríveis, e eu já marquei várias vezes para Dr. Marcelo e ela falta no dia do tratamento. Aí você percebe o quê?

Essa mãe tem o dente estragado e as crianças todas também e ela não se preocupa com escovação (Isabella,

ACS).

A qualidade do cuidado familiar, nos aspectos físico e afetivo-social, decorre de condições estáveis de vida, tanto socioeconômicas quanto psicossociais ${ }^{10}$. Esta é uma realidade percebida nesta comunidade, e os resultados do estudo epidemiológico também apontam nesse sentido: características socioeconômicas familiares e ambien- 
Tabela 3. Associações brutas, Razões de Prevalência e seus respectivos Intervalos de Confiança a 95\%, entre condições de vida (características demográficas, socioeconômicas e ambientais), estilo de vida (características relacionais familiares) e cárie dentária em pré-escolares, Salvador-BA, 2007 ( $n=528)$.

\begin{tabular}{|c|c|c|c|c|c|c|c|}
\hline Variáveis & $R^{2}$ & IC $95 \%$ & $\begin{array}{c}\text { p- } \\
\text { valor }\end{array}$ & Variáveis & $\mathbf{R P}^{2}$ & IC $95 \%$ & $\begin{array}{l}\text { p- } \\
\text { valor }\end{array}$ \\
\hline $\begin{array}{l}\text { Condições de vida - } \\
\text { caracteristicas demográficas e } \\
\text { socioeconômicas }\end{array}$ & & & & $\begin{array}{l}\text { Condiçōes de vida - } \\
\text { características ambientais }\end{array}$ & & & \\
\hline $\begin{array}{l}\text { Gênero } \\
\text { Feminino } \\
\text { Masculino }\end{array}$ & $\begin{array}{l}1.00 \\
1.06\end{array}$ & $0.7 \overline{1.56}$ & 0.759 & $\begin{array}{l}\text { Número de cômodos } \\
5 \text { ou mais } \\
\text { Menos de } 5\end{array}$ & $\begin{array}{l}1.00 \\
1.18\end{array}$ & $0.8 \overline{1} 1.73$ & 0.394 \\
\hline $\begin{array}{l}\text { Idade } \\
\text { Menos de } 33 \text { meses } \\
33 \text { meses ou mais }\end{array}$ & $\begin{array}{l}1.00 \\
3.05\end{array}$ & $1.9 \overline{24.83}$ & 0.000 & $\begin{array}{l}\text { Tipo de casa } \\
\text { Tijolo } \\
\text { Outros }\end{array}$ & $\begin{array}{l}1.00 \\
3.16\end{array}$ & $1.65 \overline{6} .06$ & 0.004 \\
\hline $\begin{array}{l}\text { Cor da pele } \\
\text { Outros } \\
\text { Negro/pardo }\end{array}$ & $\begin{array}{l}1.00 \\
2.01\end{array}$ & $0.9 \overline{4} .19$ & 0,048 & $\begin{array}{l}\text { Coleta do lixo } \\
\text { Coletado } \\
\text { Outros }\end{array}$ & $\begin{array}{l}1.00 \\
1.09\end{array}$ & $0.5 \overline{2} .10$ & 0.806 \\
\hline $\begin{array}{l}\text { Renda familiar } \\
\text { Mais que } 2 \mathrm{SM}^{\prime} \\
\text { Até } 2 \mathrm{SM}^{2}\end{array}$ & $\begin{array}{l}1.00 \\
1.62\end{array}$ & $1.02 \overline{2.58}$ & 0.037 & $\begin{array}{l}\text { Estilo de vida - } \\
\text { caracteristicas relacionais } \\
\text { Cuidador em casa } \\
\text { Māe } \\
\text { Avờ Outros }\end{array}$ & $\begin{array}{l}1.00 \\
0.86\end{array}$ & $0.5 \overline{2} 1.41$ & 0.539 \\
\hline $\begin{array}{l}\text { Escolaridade materna } \\
2^{\circ} \text { grau ou mais } \\
2^{\circ} \text { grau incompleto ou menos }\end{array}$ & $\begin{array}{l}1.00 \\
1.82\end{array}$ & $1.1 \overline{2} .84$ & 0.006 & $\begin{array}{l}\text { Relação mäe-filho } \\
\text { Mora com a mãe } \\
\text { Outros }\end{array}$ & $\begin{array}{l}1.00 \\
1.73\end{array}$ & 1.092 .75 & 0.025 \\
\hline $\begin{array}{l}\text { Total de eletrodomèsticos } \\
\text { Mais do que } 6 \\
\sigma \text { ou menos }\end{array}$ & $\begin{array}{l}1.00 \\
1.51\end{array}$ & $1, \overline{002,27}$ & 0.043 & $\begin{array}{l}\text { Situaçāo conjugal materna } \\
\text { Casadal vive com } \\
\text { companheiro } \\
\text { Outros }\end{array}$ & $\begin{array}{l}1.00 \\
1.19\end{array}$ & $0.80 \overline{1.77}$ & 0.403 \\
\hline $\begin{array}{l}\text { Nủmero moradores por cömodo } \\
\text { Até } 1 \text { pessoa por cốmodo } \\
\text { Mais de } 1 \text { pessoa por cómodo }\end{array}$ & $\begin{array}{l}1.00 \\
1.49\end{array}$ & $1, \overline{012}, 18$ & 0,042 & $\begin{array}{l}\text { Irmāos na faixa etäriada } \\
\text { criança } \\
\text { Nāó } \\
\text { Sim }\end{array}$ & $\begin{array}{l}1.00 \\
0.77\end{array}$ & $0.4 \overline{1.33}$ & 0.342 \\
\hline $\begin{array}{l}\text { Chefe da familia } \\
\text { Companheirol casal } \\
\text { Mäeloutros }\end{array}$ & $\begin{array}{l}1.00 \\
1.20\end{array}$ & $0 . \overline{1} 1.77$ & 0.367 & & & & \\
\hline
\end{tabular}

${ }^{1}$ Salário Mínimo

${ }^{2}$ Razão de Prevalência

${ }^{3}$ Intervalo de Confiança a 95\%

${ }^{4}$ Valor de $\mathrm{p}$ obtido pelo Teste Qui-Quadrado de Pearson

tais como renda familiar ( $R P=1,62$, IC $95 \% 1,022,58$ ), escolaridade materna ( $R P=1,82$, IC $95 \% 1,172,84)$, número de moradores por cômodo ( $\mathrm{RP}=1,49$, IC $95 \%$ 1,01 2,18) e o tipo de casa ( $R P=3,16$, IC $95 \% 1,656,06)$ apresentaram associações positivas e estatisticamente significantes com a presença de cárie dentária em pré-escolares (Tabela 3).

A literatura epidemiológica apresenta achados consistentes para a relação entre fatores socioeconômicos e ambientais e ocorrência de cárie precoce: a baixa escolaridade dos pais representa um dos elementos associados à doença $3,4,5$, assim como a renda familiar, classe social e ocupação dos pais ${ }^{4,5}$.

A presença de alterações psicossociais maternas, identificadas por presença de alcoolismo, esteve positivamente associada com a cárie ( $R P=1,60$, IC 95\% 1,05 2,46) (Tabela 4). Recentemente, estudos apontam na direção de associações positivas entre aspectos psicossociais familiares, como: estresse familiar, senso de coerência materno, alterações psiquiátricas maternas e alcoolismo de mem- bros da família e cárie dentária em pré-escolares ${ }^{15,} 31,32$.

As dificuldades encontradas pelas mães para o cuidado com a saúde bucal dos filhos relacionam-se à necessidade de terem uma vida profissional e à falta de apoio do companheiro.

Olhe, de saber eu sei. Eu sei como é, mas não vou mentir, né? Porque eu mal, quando trabalhava, eu mal comprava escova pra os meninos. Levava a escova pra casa da menina, a menina não escovava. Eu perguntava. Eu sei que tem que ficar cobrando de escovar. Acabou de almoçar, tem que escovar; antes de dormir, tem que escovar. Eu sei disso tudo, mas a gente que trabalha, tem que trabalhar, né? É difícil de a gente cumprir esses horários. Quê que adianta? Mas de saber, eu sei como é, ainda agora eu escovei o dente dele [refere-se ao filho], entendeu? Quando tem tempo faz, quando não tem tempo deixa com o pai. O pai dele não tem nada na cabeça, esquece e não faz. Aí, de manhã todo mundo se lembra... (Priscila, mãe). 
Tabela 4. Associações brutas, Razões de Prevalência e seus respectivos Intervalos de Confiança a 95\%, entre estilo de vida (características comportamentais e acesso a atenção odontológica), alterações psicossociais maternas e cárie dentária em pré-escolares, Salvador-BA, 2007 ( $n=528)$.

\begin{tabular}{|c|c|c|c|c|c|c|c|}
\hline Variáveis & $\mathbf{R P}^{1}$ & IC $95 \%^{2}$ & $\begin{array}{c}\text { p- } \\
\text { valor }^{3}\end{array}$ & Variáveis & $\mathbf{R P}^{1}$ & IC $95 \%^{2}$ & p-valor ${ }^{3}$ \\
\hline \multirow{2}{*}{\multicolumn{4}{|c|}{$\begin{array}{l}\text { Estilo de vida - características } \\
\text { comportamentais e acesso a } \\
\text { atenção odontológica } \\
\text { Amamentação notuma }\end{array}$}} & \multicolumn{4}{|l|}{$\begin{array}{l}\text { Alterações psicossociais } \\
\text { maternas }\end{array}$} \\
\hline & & & & \multicolumn{4}{|l|}{ Alteração psiquiátrica } \\
\hline Não & 1,00 & $\ldots$ & \multirow{2}{*}{0,226} & Ausente & 1,00 & $\ldots$ & \multirow{2}{*}{0,615} \\
\hline Sim & 1,27 & $0,861,86$ & & Presente & 1,11 & $0,741,67$ & \\
\hline Tempo de aleitamento materno & & & \multirow{3}{*}{0,274} & Alcoolismo & & & \multirow{3}{*}{0,034} \\
\hline 6 meses ou mais & 1,00 & $\ldots$ & & Ausente & 1,00 & $\ldots$ & \\
\hline Menos que 6 meses & 0,81 & $0,551,19$ & & Presente & 1,60 & $1,05 \quad 2,46$ & \\
\hline Consumo de alimentos doces & & & \multirow{3}{*}{0,110} & Domínio físico ${ }^{4}$ & & & \multirow{3}{*}{0,269} \\
\hline Não & 1,00 & $\ldots$ & & Satisfatório & 1,00 & & \\
\hline Sim & 1,59 & $0,88 \quad 2,89$ & & Insatisfatório & 1,25 & $0,851,84$ & \\
\hline Freqüência diária de escovação & & & \multirow{3}{*}{0,154} & Domínio psicológico ${ }^{4}$ & & & \multirow{3}{*}{0,797} \\
\hline 2 vezes ou mais & 1,00 & $\ldots$ & & Satisfatório & 1,00 & $\ldots$ & \\
\hline Menos de 2 vezes & 1,32 & $0,90 \quad 1,95$ & & Insatisfatório & 1,05 & $0,711,55$ & \\
\hline Início da higiene bucal & & & \multirow{3}{*}{0,085} & Domínio ambiental $^{4}$ & & & \multirow{3}{*}{0,771} \\
\hline Menos de 6 meses & 1,00 & $\ldots$ & & Satisfatório & 1,00 & 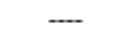 & \\
\hline 6 meses ou mais & 1,48 & $0,94 \quad 2,33$ & & Insatisfatório & 1,06 & $0,70 \quad 1,62$ & \\
\hline Atenção odontológica & & & \multirow{3}{*}{0,008} & Domínio relações sociais ${ }^{4}$ & & & \multirow{3}{*}{0,332} \\
\hline Sim & 1,00 & $\ldots$ & & Satisfatório & 1,00 & $\ldots$ & \\
\hline Não & 0,60 & $0,41 \quad 0,87$ & & Insatisfatório & 1,21 & $0,82 \quad 1,78$ & \\
\hline
\end{tabular}

${ }^{1}$ Razão de Prevalência

${ }^{2}$ Intervalo de Confiança a $95 \%$

${ }^{3}$ Valor de p obtido pelo Teste Qui-Quadrado de Pearson

${ }^{4}$ Domínios da Qualidade de Vida Materna, segundo classificação do WhoQol-bref

Mães entrevistadas por Robles, Grosseman e Bosco ${ }^{27}$ mencionaram a vida profissional, a jornada de trabalho e as dificuldades financeiras como fatores que comprometem a prestação dos cuidados em saúde bucal necessários aos fiIhos. Mesmo sendo bem informadas, a rotina e a falta de tempo interferiam nos cuidados com a saúde bucal infantil. Em um depoimento deste mesmo estudo, a culpa pela precária situação bucal do filho foi relacionada ao cuidado materno inadequado. Segundo Abreu, Pordeus e Modena ${ }^{26}$, sentimentos negativos são gerados nas mães quando ocorre a cobrança da sociedade em relação aos cuidados com os fiIhos e os mesmos não podem ser cumpridos, prejudicando inclusive sua qualidade de vida. Erroneamente, em certos momentos a literatura reforça a culpabilização dos pais pelas condições de saúde bucal de seus filhos, ao apontar suas características socioeconômicas, práticas e crenças como causas diretas das afecções infantis, quando na realidade existe uma confluência de múltiplos fatores que contribuem para o estado bucal infantil ${ }^{33}$. Esta realidade deve ser levada em conta pelos profissionais de saúde ao aconselhar os pais, para que conjuntamente sejam planejadas estratégias de atenção à saúde bucal infantil.

Para os profissionais de saúde a implantação da Estratégia Saúde da Família nesta comunidade vem contribuindo para a mudança de crenças e de cuidados relacionados à dentição decídua.
"Criança não escova dente, pra quê escova dente de menino?" [refere-se às idéias das pessoas no passado]. Agora com os PSF da vida que nós levamos a informação, nós fazemos as palestras que elas [refere-se às famílias] tiveram consciência que apesar de criança, tem que ser cuidada como adulto, não é?

(Silvia, ACS).

Inclusive tem umas [refere-se às famílias] que nem escova compravam pras crianças, por acharem que criança não precisava. (...) Há algumas crianças que não usavam escova ou quando usavam, era uma escova pra 05 crianças na mesma casa (Isabella, ACS).

Alguns indicadores de saúde da criança sofreram impacto positivo com a implantação da Saúde da Família em municípios do Nordeste brasileiro ${ }^{34}$. Nesse contexto, deve-se destacar o papel dos ACS, cujas práticas educativas realizadas nas comunidades são capazes de influenciar as percepções e o conhecimento sobre saúde bucal $^{35}$.

\section{CONCLUSÃO}

A família é o núcleo social inicial de desenvolvimento do ser humano ${ }^{7}$. Os participantes deste estudo consideraram que a família é aparato de cuidado essen- 
cial ao desenvolvimento e saúde dos seus membros, sendo fundamental o papel das mães no cuidado com as crianças pequenas. As condições de saúde bucal deste grupo, por sua vez, ainda são marcadas pela prevalência e gravidade da cárie dentária.

O modo de vida familiar, caracterizado por suas condições de vida materiais, como renda e escolaridade, e estilo de vida, marcado por atitudes comportamentais relacionaram-se com o desenvolvimento da cárie em pré-escolares. $\mathrm{O}$ alcoolismo materno associou-se positivamente com a presença desta doença nas crianças residentes em áreas cobertas pela Estratégia Saúde da Família de Salvador-BA. Tal alteração psicossocial compromete a adequação do cuidado necessário para a manutenção da saúde bucal infantil.

A cárie precoce é percebida como um problema importante pelas mães, avós e profissionais de saúde bucal da área da USF participante deste estudo, os quais acreditam que fatores biológicos e comportamentais são os principais causadores desta doença, apesar de alguns apresentarem crenças que vão de encontro ao conhecimento científico, como a de que a cárie é um processo natural e inevitável e de que medicamentos podem provocar o aparecimento de lesões cariosas. Os profissionais de saúde bucal percebem a influência da relação entre as condições materiais e afetivas do ambiente familiar nos cuidados com a saúde bucal, que segundo as mães é dificultado pela vida profissional e falta de apoio social.

A causalidade da cárie dentária na dentição decídua associa-se a múltiplos fatores, além dos limites do setor saúde, daí a importância de ações intersetorias para a promoção de saúde bucal infantil, as quais devem passar pela reorientação de políticas públicas que garantam renda, trabalho e bons níveis de escolaridade, até a reorientação dos serviços de saúde, que devem garantir a universalidade, eqüidade e integralidade da atenção. Nesse sentido, estratégias de acolhimento nos serviços, como a escuta profissional qualificada, capaz de perceber o entendimento dos usuários sobre o processo saúde-doença além do pensamento biomédico, possibilitam a autonomia de sujeitos e o planejamento compartilhado de ações de saúde bucal coletiva.

Do ponto de vista metodológico, Minayo e Sanches ${ }^{13}$ relatam que não há contradição entre as abordagens metodológicas qualitativa e quantitativa na pesquisa em saúde. Em busca de uma maior compreensão das relações sociais, culturais e os agravos à saúde, é desejável uma maior integração destas abordagens, utilizando-se das suas principais potencialidades. Este estudo buscou esta integração ao considerar que os problemas de saúde coletiva resultam de um complexo de causas e que diferentes metodologias ajudam a conhecê-las.

Na perspectiva epidemiológica, sabe-se que o desenho de corte transversal empregado neste estudo não é adequado para a investigação de causalidade e que neste caso seu objetivo foi estritamente descritivo; na perspectiva qualitativa os grupos focais apresentam vantagens em relação a outras técnicas de produção de dados: em sua essência, o grupo é mais do que a soma das partes, pois ocorrem processos dentro deles que não são vistos na interação diádica da entrevista individual em profundidade; a partilha e o contraste de experiências constroem um quadro de interesses e preocupações comuns que raramente seriam articuladas por um único indivíduo. Entretanto, o controle da entrevista por parte do pesquisador é mais difícil em um grupo focal que em uma estratégia de coleta individual, exigindo habilidades do moderador para condução do grupo; alguns grupos podem apresentar-se sem interesse na discussão, daí a importância de vários grupos focais ${ }^{21}$.

Por fim, acredita-se que as pesquisas em saúde serão mais efetivas, do ponto de vista de suas repostas sociais, quando passarem a ser mais permeáveis à utilização dos diferentes métodos.

\section{REFERÊNCIAS}

1. ANTUNES, J.L.F.; PERES, M.A.; MELLO, T.R.C. Determinantes individuais e contextuais da necessidade de tratamento odontológico na dentição decídua no Brasil. Ciênc. Saúde Coletiva., Rio de Janeiro, v.11, n.1, p.79-87, 2006.

2. AMERICAN ACADEMY OF PEDIATRIC DENTISTRY. Policy on early childhood caries (ECC): classifications, consequences and prevention strategies.. Disponível em: <http://www.aapd.org/media/Policies_ Guidelines/D_ECC.pdf>. Acesso em:05 mai. 2010

3. CABRAL, MBBS. Situação de saúde bucal em um grupo de crianças menores de $\mathbf{3 0}$ meses que freqüentam creches públicas, privadas e filantrópicas em Salvador-BA. 2005. Tese (Doutorado) - Instituto de Saúde Coletiva, Universidade Federal da Bahia, Salvador, 2005.

4. PERES, M.A. et al. Social and biological early life influences on severity of dental caries in children aged 6 years. Community Dent. Oral Epidemiol., Copenhagen, v.33, n.1, p.53-63, 2005.

5. HARRIS, R et. al. Risk factors for dental caries in young children: a systematic review of the literature. Community Dent. Health., London, v. 21 , suppl. 1, p. 71-85, 2004.

6. REISINE, S.; DOUGLAS, J.M. Psychosocial and behavioral issues in early childhood caries. Community Dent Oral Epidemiol, London, v.26, suppl 1, p.32-44, 1998.

7. BRONFENBRENNER, U. Ecology of the family as a context for human development: research perspectives. Dev. Psychol., Washington, v. 22, n.6, p.723-42, 1986.

8. OLIVEIRA, M.L.S., BASTOS, A.C.S. Práticas de atenção à saúde no contexto familiar: um estudo comparativo de casos. Psicol. Reflex. Crit, Porto Alegre, v.13, n.1, p.97-107, 2000.

9. ALMEIDA FILHO, N.M. A Ciência da Saúde. São Paulo: Hucitec, 2000. $255 \mathrm{p}$.

10. ANDRADE,A.S. Ambiente familiar e desenvolvimento infantil: uma abordagem epidemiológica. Rev. Saúde Pública, São Paulo, v.39, n.4, p.606-11, 2005.

11. ALMEIDA, T.F. Contexto familiar e saúde bucal de pré-escolares: uma revisão sistemática com ênfase nos fatores psicossociais. 2011. Tese (Doutorado). Instituto de Saúde Coletiva, Universidade Federal da Bahia, Salvador, 2011.

12. BARDAL, P.A.P. Cárie dentária em crianças como fenômeno natural 
ou patológico: ênfase na abordagem qualitativa. Ciênc. Saúde Coletiva., Rio de Janeiro, v.11, n.1, p.161-67, 2005

13. MINAYO, M.C.S.; SANCHES, O. Qualitativo-Quantitativo: oposição ou complementaridade. Cad Saúde Pública, Rio de Janeiro, v.9, n.3, p.239-62, 1993.

14. DEAN, A.G.et al.. Epi Info, version 6: a word processing, database and statistic program for epidemiology on microcomputers. Atlanta,Georgia, USA: Center for Disease Control and Prevention ,1994.

15. SOUZA, M.A.; VIANNA, M.I.P; CANGUSSU, M.C.T. Disfunção familiar referida pela presença de depressão materna e/ou alcoolismo na família e ocorrência de cárie dentária em crianças de dois e três anos de idade. Rev. Bras. Saúde Matern. Infant. Recife, v.6, n.2, p.309-1, 2006.

16. OLIVEIRA, A.G.R.C. Impacto do Programa Saúde da Família no perfil de saúde bucal: análise em municípios do Nordeste com mais de 100 mil habitantes. 2006. Projeto de Pesquisa, Universidade Federal do Rio Grande do Norte, Natal, 2006.

17. WORLD HEALTH ORGANIZATION. Division of Mental Health. A user's guide to Self Report Questionnaire (SRQ). Geneva, 1994.

18. EWING, .J.A; ROUSE, B.A. Identifying the hidden alcoholic. In: INTERNATIONAL CONGRESS ON ALCOHOL AND DRUG DEPENDENCE,29,1970, Sidney, Australia, Anais... Sidney, Australia,1970.

19.ORGANIZAÇÃO MUNDIAL DE SAÚDE. Levantamento epidemiológico básico de saúde bucal. 4 ed. São Paulo: Santos, 1999. 53 p.

20. STATA. Data Analysis and Statistical Software: Release 10.[S.I]: StataCorp LP, 2007. Disponível em:< http://www.stata.com/stata10/>

21. KRUEGER, R.A. Focus Groups: a practical guide for applied research. 4 th. ed. London: Sage, 1988. 220p.

22. MINAYO, M.C.S. O desafio do conhecimento: pesquisa qualitativa em saúde. 9a ed. São Paulo: Hucitec, 2006. 406 p.

23. BRASIL. Ministério da Saúde. Secretaria de Atenção à Saúde. Departamento de Atenção Básica. Coordenação Nacional de Saúde Bucal. Projeto SB Brasil 2003. Condições de saúde bucal da população brasileira 2002-2003. Resultados preliminares. Brasília: Ministério da Saúde, 2004.

24. ALMEIDA, T.F. et al. Condições de saúde bucal de crianças na faixa etária pré-escolar, residentes em áreas de abrangência do Programa Saúde da Família em Salvador, Bahia, Brasil. Rev. Bras. Saúde Matern. Infant, Recife, v.9, n.3, p.147-52, 2009.

25. NATIONS, M.K. et al. Cultural significance of primary teeth for caregivers in Northeast Brazil. Cad. Saúde Pública, Rio de Janeiro, v.24, n. 4, p.800-8, 2008.

26. ABREU, MHNG; PORDEUS, I.A, MODENA, C.M. Representações sociais de saúde bucal entre mães do meio rural de Itaúna (MG), 2002. . Ciênc. Saúde Coletiva., Rio de Janeiro, v.10, n.1, p.245-59, 2005.

27. ROBLES, ANC; GROSSEMAN, S; BOSCO, VL. Práticas e significados de saúde bucal: um estudo qualitativo com mães de crianças atendidas na Universidade Federal de Santa Catarina. Ciênc. Saúde Coletiva.,Rio de Janeiro, p.43-9, 2008. Disponível em: http://www/abarsco.org.br/ cienciaesaudecoletiva/artigos/artigo_int.phpid_artigo=1580 Acesso em: 18 mar. 2009.

28. LACERDA, J.T. Impacto da saúde bucal na qualidade de vida. 2005. 196 f. Tese (Doutorado) - Faculdade de Medicina, Departamento de Medicina Preventiva, Universidade de São Paulo, São Paulo, 2005.

29. HILTON, I.V.et. al. Cultural factors and children's oral health care: a qualitative study of carers of young children. Community Dent. Oral Epidemiol., Copenhagen, v.35, n.6, p.429-38, 2007.

30. BUSTAMANTE, V.; BOMFIM, L.A.Cuidando da saúde de crianças pequenas no contexto familiar: um estudo etnográfico com famílias de camadas populares. Ciência e Saúde Coletiva, Rio de Janeiro, v.12, n. 5 , p. $1175-84,2007$

31. ISMAIL, A.I. Predictors of dental caries progression in primary teeth. J. Dent. Res., Washington, v.88, n.3, p.270-75, 2009.

32. BONANATO K, PAIVA S.M. Relationship between sense of coherence and oral health status of preschool children. Caries Res. , Basel, v.43, n.2, p.103-09, 2004

33. BARKER, C.; HORTON, S.B. An ethnographic study of Latino preschool children's oral health in rural California: Intersections among family, community, provider and regulatory sectors. BMC Oral Health, Londres, v. 8, n. 8, 2008. Disponível em: <http://www.biomedcentral.com/14726831/8/8>. Acesso em: 14 set. 2008.

34. RONCALLI ,A.G.; LIMA, K.C. Impacto do Programa Saúde da Família sobre indicadores de saúde da criança em municípios de grande porte da região Nordeste do Brasil. Ciênc. Saúde Coletiva., Rio de Janeiro, v.11, n.3, p.713-24, 2006

35. FRAZÃO, P.; MARQUES, D.S.C. Influência de agentes comunitários de saúde na percepção de mulheres e mães sobre conhecimento de saúde bucal. Ciênc. Saúde Coletiva., Rio de Janeiro,v.11, n.1, p.131-44, 2006.

Submetido em 14.11.2012;

Aceito em 02.04.2013. 